\title{
COMUNIDADE FITOPLANCTÔNICA DE UMA LAGOA EUTROFIZADA (LAGOA GRANDE), FEIRA DE SANTNA, BAHIA
}

\author{
João Teixeira Xavier Neto'; Carlos Wallace do Nascimento Moura ${ }^{2}$ \\ 1. Bolsista PIBIC/FAPESB, Bacharelado em Ciências Biológicas, Universidade Estadual de Feira de Santana, \\ e-mail: joaoteixeiraxavierneto@gmail.com \\ 2. Orientador, Departamento de Ciências Biológicas, Universidade Estadual de Feira de Santana, \\ e-mail:wallace@uefs.br
}

PALAVRAS-CHAVE: Algas, Fitoplâncton, Taxonomia.

\section{INTRODUÇÃO}

Nos ecossistemas aquáticos o fitoplâncton, composto por microrganismos fotossintetizantes com tamanho variando desde $0,2 \mu \mathrm{m}$ a $2000 \mu \mathrm{m}$ comprimento e de morfologia diversa, constituído a base da cadeia alimentar em ambientes aquáticos, desempenhando assim um importante papel no equilíbrio e metabolismo do sistema (Esteves 1998, Beyruth 1996, Reynolds 2006).

Alterações naturais nas propriedades físicas e químicas da água, além do input de fósforo e nitrogênio oriundos de atividades antrópicas costumam acarretar floração ou blooms de microalgas no ambiente, com destaque para os grupos das Chlorophyta, Eulenophyta, Bacillariophyta e Cyanobacteria, estas últimas consideras como bioindicadores de sistemas antrópicos, o que tende a acarretar uma série de problemas e consequentemente ocasionando anoxia no sistema (Alcântara et al. 2011, Esteves 1998).

O município de Feira de Santana apresenta várias lagoas no seu entorno (FrancaRocha \& Nolasco 1998), entretanto, com a expansão urbana deste algumas se tornaram periurbanas e outras do centro urbano desapareceram. Recentemente, a lâmina d'água da Lagoa Grande foi recuperada pelo governo do Estado visando promover o bem-estar da população. Contudo, a água desta é imprópria para a recreação devido à entrada de esgotos, que pode levar o crescimento exagerado de microalgas acarretando a mortandade de peixes além promover odor desagradável.

Diante disso, e dado a carência de estudos da comunidade fitoplanctônica ocorrentes nas lagoas urbanas de Feira de Santana, o presente estudo visa conhecer as espécies de algas e cianobactérias presentes na Lagoa Grande e contribuir para estudos futuros que demandem do conhecimento da biodiversidade local.

\section{MATERIAL E MÉTODOS OU METODOLOGIA}

As algas e cianobactérias fitoplanctônicas foram coletadas bimestralmente durante o período de agosto de 2017 a junho de 2018, de modo a abranger períodos de chuva e seca, em nove pontos equidistantes localizados na margem da Lagoa Grande, totalizando 52 amostras no fim dos trabalhos.

A coleta do material foi realizada de acordo com os métodos usuais empregados em estudos de taxonomia de microalgas continentais (Bicudo \& Menezes 2017), sendo as amostras coletadas com rede de plâncton com malha de $20 \mu \mathrm{m}$ de abertura.

Imediatamente após a coleta, o material foi fixado em solução de Transeau (Bicudo \& Menezes 2017) visando preservar os cloroplastídeos, imprescindíveis na identificação de alguns táxons. 
Os dados abióticos da água como temperatura, $\mathrm{pH}$, condutividade foram mensurados com auxílio do equipamento multiparâmetro Hanna Instruments (Hanna HI98130), enquanto os dados de oxigênio dissolvido foram mensurados com o auxílio do equipamento digital portátil da Instrutherm (MO-910).

As amostras foram analisadas entre lâmina e lamínula com auxílio do microscópio óptico binocular marca LEICA (modelo DM LS2) ou Olympus (modelo BX43), visando observar as características morfológicas e métricas das populações. A identificação foi baseada em trabalhos especializados, incluindo floras, revisões, dissertações e teses.

A riqueza taxonômica foi determinada pelo número total de espécies amostradas. A frequência de ocorrência dos táxons foi calculada de acordo com a fórmula: $\mathrm{F}=\mathrm{n} .100 / \mathrm{N}$, onde $n$ é número de amostras em que uma espécie foi registrada, $N$ total de amostras analisadas. As categorias de frequência foram determinados de acordo com Matteucci \& Colma (1982): $>70 \%$ - Muito frequente (MF); $\leq 70 \%$ e $>40 \%$ - Frequente $(\mathrm{FR}) ; \leq 40 \%$ e $>10 \%$ - incomum $(\mathrm{I}) ; \leq 10 \%$ - Rara $(\mathrm{R})$.

\section{RESULTADOS E DISCUSSÃO}

Após a análise das 52 unidades amostrais, coletadas em nove pontos da Lagoa Grande, Feira de Santana, foram identificados 33 táxons de algas e cianobactérias fitoplanctônicos, sendo 30 identificados a nível infraespecífico e três táxons a nível de gênero (Aphanocapsa sp., Crucigeniella sp., Trachelomonas sp.), distribuídos em seis classes, seis ordens, 11 famílias e 21 gêneros.

Dentre os táxons identificados, 8 são novos registros para a Bahia (Aphanocapsa delicatissima, Tetradesmus cf. dimorphus, Desmodesmus intermediius var. acutipinus, Scenedesmus apiculatus, Scenedesmus heteracanthus, Scenedesmus polydenticulatus, Lepocinclis acus var. longissima, Euglena polymorpha).

$\mathrm{Na}$ área estudada, a classe a melhor representada foi Chlorophyceae com 19 táxons, correspondendo a $57 \%$ da riqueza florística relativa, seguida por Trebouxyophyceae (15\%), Euglenophyceae (13\%), Cyanophyceae (9\%) e Mediophyceae e Xantophyceae, com 3\% cada. Dente as ordens inventariadas, a melhor representada foi Sphaeropleales (Chlorophyceae) com quatro famílias, nove gêneros e 19 táxons, dos quais dez $(73,5 \%)$ pertencentes à Scenedesmaceae. Os gêneros mais representativos foram Desmodesmus e Scenedesmus, com cinco táxons cada, seguidos por Tetradesmus (3), Aphanocapsa e Trachelomonas (2) e os demais gêneros com 1 táxon cada.

Constatou-se que cerca de $42,5 \%$ da comunidade de algas e cianobactérias fitoplanctônicas encontradas na lagoa é de ocorrência incomum $(\leq 40 \%$ e $>10 \%)$, e apenas sete táxons (Aphanocapsa sp., Merismopedia tranquila, Tetradesmus lagerheimii, Monoraphidium circinale, Tetraëdron triangulare, Golenkinia radiata e Cyclotella meneghiniana) ocorreram em mais de $70 \%$ do total de amostras analisadas.

Analisando a frequência de ocorrência e as variáveis ambientais em que as algas e cianobactérias na Lagoa Grande foram encontradas (Tab. 1), constatou-se que a maioria dos táxons ocorreram em condições de micro-habitat com $\mathrm{pH}$ básico, baixa condutividade e temperatura elevada, e que a entrada de nutrientes através de esgotos domésticos na lagoa provavelmente propiciou a abundância clorofíceas (Tetradesmus lagerheimii, Monoraphidium circinale, Tetraëdron triangulare, Golenkinia radiata), cianobactérias (Aphanocapsa sp., Merismopedia tranquila) e diatomáceas (Cyclotella meneghiniana).

Os resultados obtidos quanto a predominância de algas clorofíceas está de acordo com estudos realizados em lagos eutrófizados por Sant'Anna et al. (1997), Bicudo et al. (1999), Tucci et al. (2006), Gentil et al. (2008). 


\section{CONSIDERAÇÕES FINAIS}

O estudo das algas e cianobactérias fitoplanctônicas coletadas Lagoa Grande, Feira de Santana, Bahia, permitiu concluir que: 1) A área apresenta uma interessante biodiversidade, sendo representada por 33 táxons; 2) oito táxons constituem novos registros para Bahia, sendo eles Aphanocapasa delicatissima, Tetrasdesmus $c f$. dimorphus, Desmodesmus intermedius var. acutispinus, Scenedesmus apiculatus, Scenedesmus heteracanthus, Scenedesmus polydenticulatus, Lepocinclis acus var. longissima, Euglena polymorpha; 3) Chlorophyceae foi a classe melhor representada com 19 taxons do total, correspondendo $57 \%$ da riqueza florística relativa, seguida por Trebouxyophyceae (15\%), Euglenophyceae (13\%), Cyanophyceae (9\%) e Medyophyceae e Xantophyceae com 3\%; 4) Os táxons mais representativos no estudo foram Aphanocapsa sp., Merismopedia tranquila, Tetradesmus lagerheimii, Monoraphidium circinale, Tetraëdron triangulare, Golenkinia radiata e Cyclotella meneghiniana, presentes em mais de $70 \%$ do total de amostras analisadas.

\section{REFERÊNCIAS}

ALCÂNTARA, S.R.S; FERREIRA, L.M.S.R.; OLIVERIA, O.C. 2011.Caraterização limnológica e comunidade fitoplanctônica da Represa do Cascão - Saboeiro - SalvadorBA. Revista Virtual 7(1): 99-108.

BICUDO, C.E.M.; MENEZES, M. 2017. Gênero de Algas de Águas Continentais do Brasil (chave para identificação e descrições). São Carlos: Rima.

FRANCA-ROCHA, W.J., NOLASCO, M.C. 1998. Projeto nascentes: um olhar sobre Feira de Santana. UEFS. Feira de Santana.

REYNOLDS, C.S. 2006. Ecology of phytoplankton. Cambridge: Cambridge University Press.

BICUDO, C.E.M., RAMÍREZ, R.J.J., TUCCI, A. \& BICUDO, D.C. 1999. A dinâmica de populações fitoplanctônicas em ambiente eutrofizado: o Lago das Garças, São Paulo. In: Henry, R. (ed.). Ecologia de reservatórios: estrutura, função e aspectos sociais. Botucatu: FUNDIBIO/ FAPESP. pp. 449-508.

GENTIL, R.C., TUCCI, A. \& SANT'ANNA, C.L. 2008. Dinâmica da comunidade fitoplanctônica e aspectos sanitários de um lago urbano eutrófico em São Paulo, SP. Hoehnea 35: 265-280

TUCCI, A., SANT'ANNA, C.L. GENTIL, R.C. \& AZEVEDO, M.T.P. 2006. Fitoplâncton do Lago das Garças, São Paulo, Brasil: um reservatório urbano eutrófico. Hoehnea 33: 147-175. 


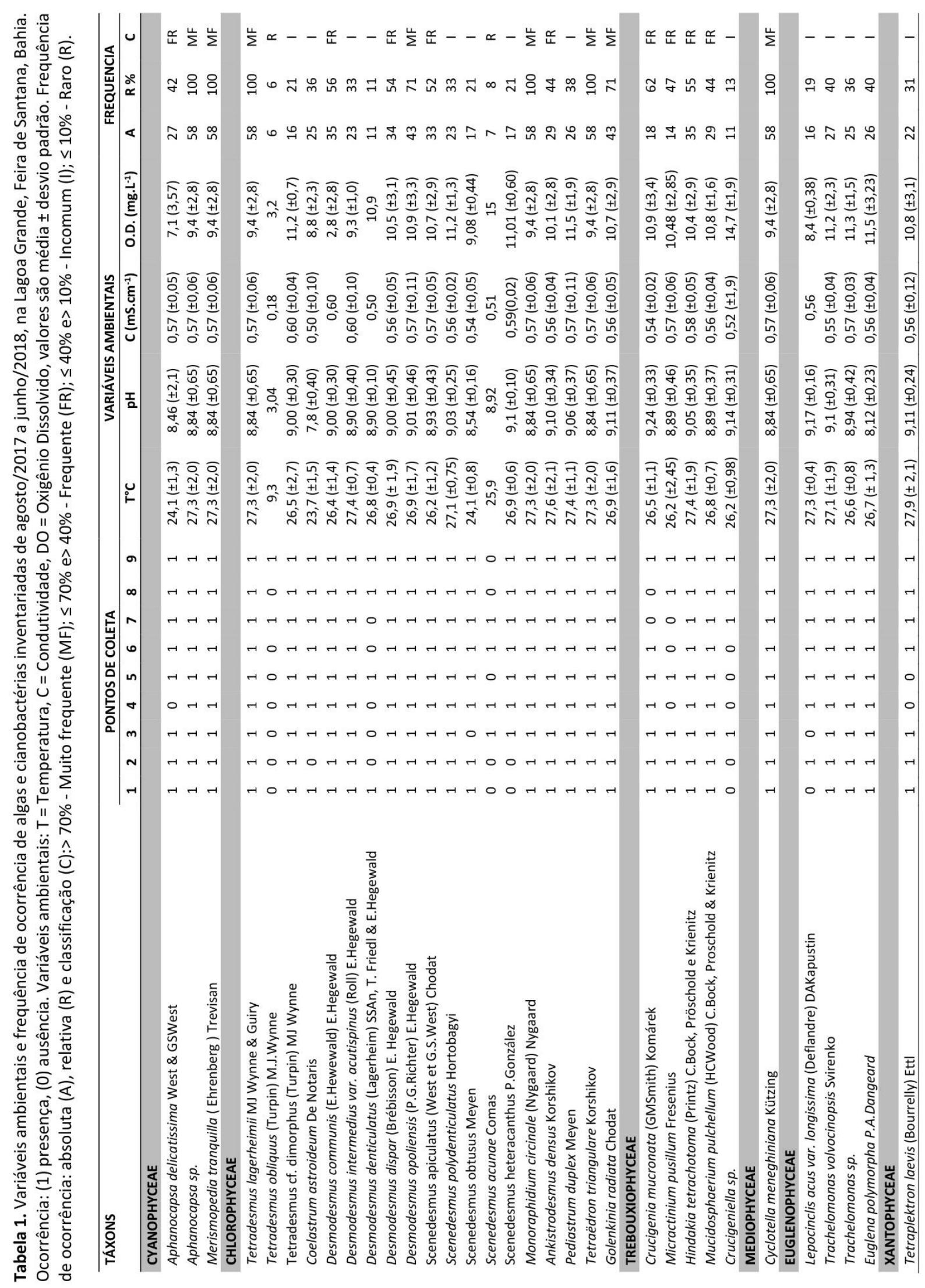

